\title{
The Relation between Lifelong Learning Tendency and Educational Philosophies
}

\author{
Hüseyin Kaygin”, Emrullah Yilmaz, Çetin Semerci \\ Department of Educational Sciences, Faculty of Education, Bartın University, Turkey
}

Copyright(C2017 by authors, all rights reserved. Authors agree that this article remains permanently open access under the terms of the Creative Commons Attribution License 4.0 International License

\begin{abstract}
This study aims to reveal the relationship between lifelong learning and philosophies of education. The sampling of the study consisted of 570 prospective teachers attending a pedagogical formation course at Bartın University and Bülent Ecevit University in 2016. Relational screening model was used in the study and the data were collected through Educational-Instructional Philosophies Determination Scale and Lifelong Learning Tendency Scale. The collected data were analysed using regression analysis via SPSS 22. According to the data obtained, there is a weak, positive correlation $(\mathrm{r}=0.286)$ between prospective teachers' lifelong learning tendency and the philosophies of education they favour at $99 \%$ confidence interval. As the standardised regression coefficient $(\beta)$ indicates, the relative order of importance of predictor values on lifelong learning tendency is as follows; essentialism, perennialism, reconstructionism and progressivism. It is observed that essentialism and perennialism are important predictors for lifelong learning tendency.
\end{abstract}

Keywords Lifelong Learning, Educational Philosophies, Relationship

\section{Introduction}

We live in an era in which everybody - from the youngest one to the oldest one - experiences a new learning nearly daily. Delors' (1996) mentioned four pillars of future education in his report for European Commission. The first one is learning to know, which means to be excel in learning and the second one is learning to do, which means learning for current conditions and unknown future conditions. The third one is learning to live together, which means developing self-awareness about other cultures and exploring new ways to eliminate racism and social exclusion. The last but not least one is learning to be, which means 'to become', 'to grow' as Lindeman (1926) asserted: "Growth is the goal of life. Power, knowledge, freedom, enjoyment, creativity - these and all other immediate ends for which we strive are contributory to the one ultimate goal which is to grow, to become"'(p.202).

20 years later one can find out that Delor's assumptions keep being globally valid. Today an individual would not live satisfactorily in his/her society unless he/she becomes a lifelong learner focused on four pillars of learning above. Chapman and Aspin (1997) summarize the objectives of lifelong learning under three headings:

(1) to create / train high-quality workforce, (2) personal development for a more successful life (3) to build a stronger society (as cited in Örs, 2016, p.88).

On the other hand, one faces with various factors throughout life that shape his/her lifelong learning experience. Schools can be considered having great impact on an individual's attitude towards lifelong learning. Throughout school life an individual has different learning experiences thanks to different teachers. Actually, parents or grandparents can be considered nearly as effective as school education on an individual's developing an attitude towards lifelong learning. All characters playing role in shaping an individual's lifelong learning philosophy may represent different educational philosophies. Therefore, an individual's lifelong learning tendency shouldn't be considered dependent from an educational philosophy. In fact, Dewey (1916) asserts that "If we are willing to conceive education as the process of forming fundamental dispositions, intellectual and emotional, toward nature and fellow men, philosophy may even be defined as the general theory of education" (p. 383). According to Ornstein (1991) our preferences on teaching are affected considerably by the philosophy of education we have already had.

This study aims to reveal the relationship between lifelong learning and philosophies of education. Essentialism, perennialism, reconstructionism and progressivism are four philosophies of education whose relationships with lifelong learning are investigated in this study. Essentialism holds that the real teaching objective is intellectual education and enlightenment (Bestor, 1955, as cited in Madaus, Kellaghan \&Schwab, 1989, p. 23). Perennialists are said to view human nature and the natural 
world as constant and unchanging. They assert that in perennialism, the most significant knowledge and skills to aid students function successfully in certain time and community are determined by teachers (Kaplan and Owings, 2015, p. 69). Progressivism claims that as a matter of fact that time shifts, world evolves, teaching shouldn't pursue same trends and should be able to adapt itself to any kind of advance (Sahu, 2002, p. 158). Moreover, it maintains that teaching should concentrate on an individual totally, that is, it should deal with him/her mentally, materially and spiritually and as a part of the society he/she lives in (Segall and Wilson, 2004, p. 162). According to reconstructionist position, student should be placed in the centre of education process (Moss and Lee, 2010). The function of the trainer in this learner-centred philosophy is to assist learners improve problem-posing skills and lifelong-learning skills (Conti, 2007). Of four educational philosophies, reconstructionism and progressivism may be considered as the closest ones to the contemporary lifelong learning description.

\section{Method}

Relational screening model was used in the study and the sampling of the study consisted of 570 prospective teachers attending a pedagogical formation course at two universities in Turkey in 2016. No sampling method was employed as all the participants were included in the study. The data were collected via educational-instructional philosophies determination scale (Semerci, Semerci and Çerçi 2002) and lifelong learning tendency scale (LLTS) (Coşkun and Demirel, 2010). The first scale used in the study is "educational-instructional philosophies determination scale (Semerci, Semerci ve Çerçi, 2002). It's a five point likert-type scale and the options range from completely disagree (1) to completely agree (5). Overall $\mathrm{KMO}$ (Kaiser-Meyer-Olkins) value of the scale is 0.77 and Bartlett's test value is 1295.055. The Cronbach's Alpha internal consistency coefficient of the scale is 0.73 . The scale included a sum of 47 items; 10 items regarding perennialism, 12 items regarding essentialism, 13 items for progressivism and 12 items for reconstructionism.

Lifelong learning tendency scale was developed by Coşkun and Demirel in 2010 in order to determine the lifelong learning tendencies of university students. The scale was administered to 642 university students attending two universities in Turkey and explanatory factor analysis was conducted to determine the construct validity. The final scale consisted of 27 items in total and four sub-dimensions (motivation, perseverance, lack of regulating learning, and lack of curiosity) were defined. The Cronbach's Alpha internal consistency coefficient of the scale was 0.89 . The total variance that all the sub-dimensions of the scale accounted for was $19.26 \%$.

The collected data were entered into SPSS 22 and analysed using regression analysis. The correlations between lifelong learning scores and educational philosophies scores of the subjects were found and interpreted. The correlations between the total scores of the sub-dimensions of educational philosophies and lifelong learning total scores were also found and interpreted.

\section{Findings}

As a result of the regression analysis, the correlations between lifelong learning tendency and educational philosophies scores of the university students involved in the study are given in Table 1 below.

Table 1. Correlations between lifelong learning tendency and educational philosophies scores

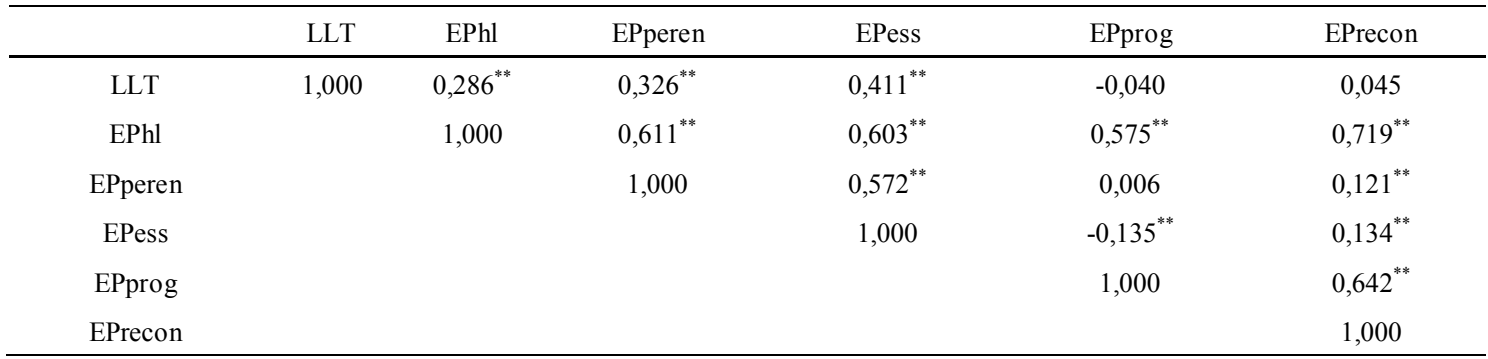

**. Correlation is significant at the 0.01 level (2-tailed). $\mathrm{p}<0.01, \mathrm{~N}=570$

LLT: Lifelong Learning Tendency, EPhl: Educational Philosophies.

As it is demonstrated in the table above, there is a weak, positive correlation $(\mathrm{r}=0.286)$ between prospective teachers' lifelong learning tendency and the philosophies of education they favour at $99 \%$ confidence interval. As for the correlation between the sub-dimensions of educational philosophies and lifelong learning, lifelong learning tendency has a significant correlation with essentialism $(\mathrm{r}=0,411)$ and perennialism $(\mathrm{r}=0,326)$ at .01 significance level. Also, it has a very weak, positive correlation with reconstructionism $(\mathrm{r}=0,045)$, which is not significant. However, it has a weak, negative correlation with progressivism $(\mathrm{r}=-0,040)$. Results of the multiple regression analysis between lifelong learning tendency and philosophies of education are shown in Table 2 below. 
Table 2. Results of multiple regression analysis on the relation between lifelong learning tendency and sub-dimensions of educational philosophies

\begin{tabular}{ccccccccc}
\hline & Model & $\mathrm{B}$ & Std. Error & $\beta$ & $\mathrm{T}$ & $\mathrm{P}$ & Zero-order & Partial \\
\hline \multirow{4}{*}{1} & (Constant) & 2,318 &, 212 & & 10,922 &, 000 & & \\
& EPperen &, 131 &, 046 &, 133 & 2,860 &, 004 &, 326 &, 119 \\
& EPess &, 283 &, 040 &, 344 & 7,064 &, 000 &, 411 &, 285 \\
& EPprog &, 030 &, 054 &, 029 &, 552 &, 581 &,- 040 &, 023 \\
& EPrecon &,- 034 &, 049 &,- 035 &,- 683 &, 495 &, 045 &,- 029 \\
\hline
\end{tabular}

Predictors: (Constant), EPperen, EPess, EPprog, EPrecon. Dependent Variable: Lifelong Learning $\mathrm{R}=0,427, \mathrm{R}^{2}=0,182, \mathrm{~F}_{(4,565)}=31,430, \mathrm{p}=.000$, Durbin-Watson (D.W.) Statistic $=1,902$

The $\mathrm{F}$ value $(31,430)$ and $\mathrm{P}$ value $(0,000<0,05)$ of regression analysis ANOVA table indicate that the model is significant at all levels. $\mathrm{R}^{2}$ value $(0,182)$ demonstrates that the $18,2 \%$ of the change in lifelong learning tendency is accounted for by four sub-dimensions of philosophies of education; essentialism, perennialism, reconstructionism and progressivism. In addition, the Durbin-Watson value $(1,902)$ suggests that there is no autocorrelation in the model. Also, lifelong learning tendency has a constant term of 2,318 without considering other variables. It is also observed in the research that one unit increase in essentialism increases the value of lifelong learning tendency by 0,283 , similarly one unit increase in perennialism raises its value by 0,131 and the same increase in progressivism by 0,030 . However, one unit increase in reconstructionism decreases the value of lifelong learning tendency by 0,034 .

As the standardised regression coefficient $(\beta)$ indicates, the relative order of importance of predictor values on lifelong learning tendency is as follows; essentialism, perennialism, reconstructionism and progressivism. It is observed that essentialism and perennialism are important predictors for lifelong learning tendency as they have a medium level, positive correlation with lifelong learning unlike the remaining two sub-dimensions. The fact that the beta value $(\beta=-0.344)$ of essentialism is higher than those of other variables with respect to its absolute value makes it a more important predictor for the model compared to others. However, progressivism and reconstructionism don't have a significant effect on lifelong learning tendency.

Taking into consideration the data given in the regression analysis above, the regression equation (mathematical model) regarding the prediction of lifelong learning tendency is given below:

$$
\text { Lifelong learning tendency }=2,318+0,131 \times \text { EPperen. }+0,283 \times \text { EPess. }+0,030 \times \text { EPprog. - 0,034 x EPrecon. }
$$

In order to demonstrate whether the relation between the predictor variables and the dependent variable is linear, the scatter plot of the multiple regressions is given in figure 1 below.

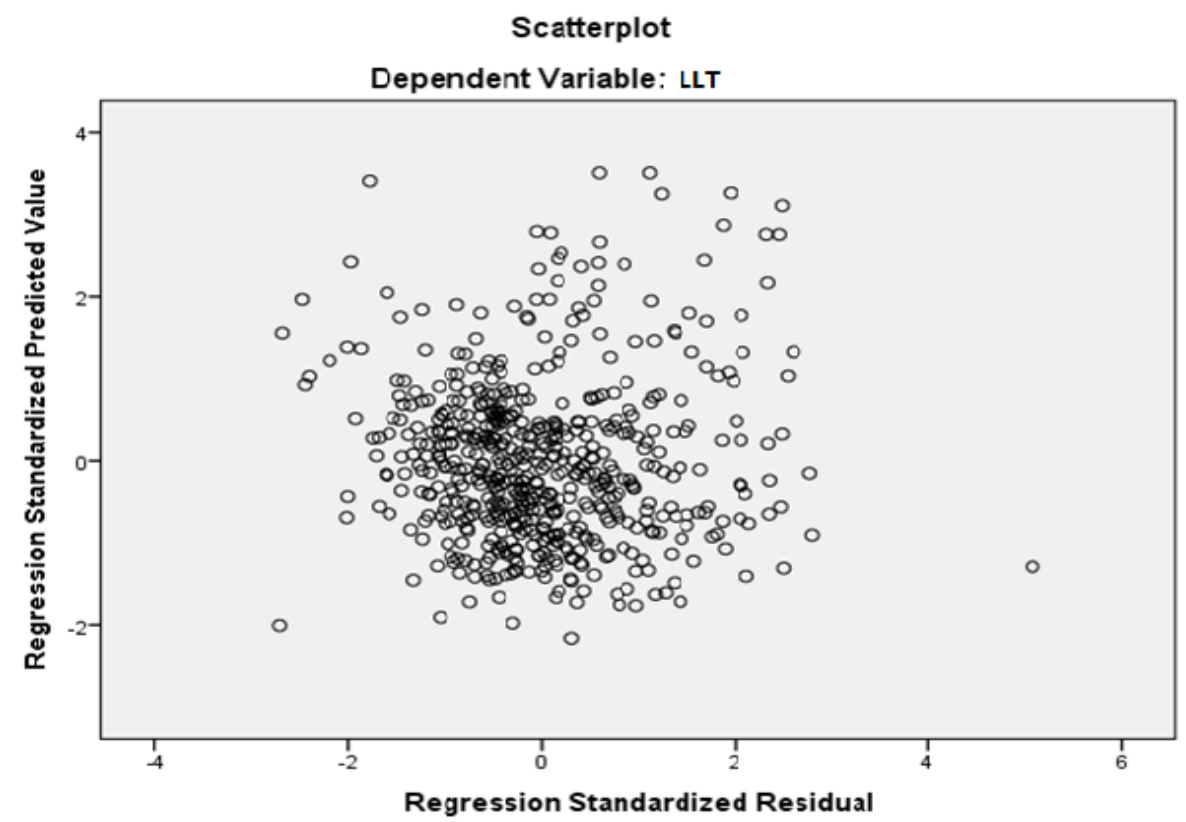

Figure 1. Scatter plot of the predictor and dependent variables

As it is observed in figure 1, the scatter plot demonstrates that the relation between predictor variables and dependent variable is linear and the dots are inclined to gather around an axis. To see whether the distribution of scores is normal, the following histogram and normal probability plot are given together. 


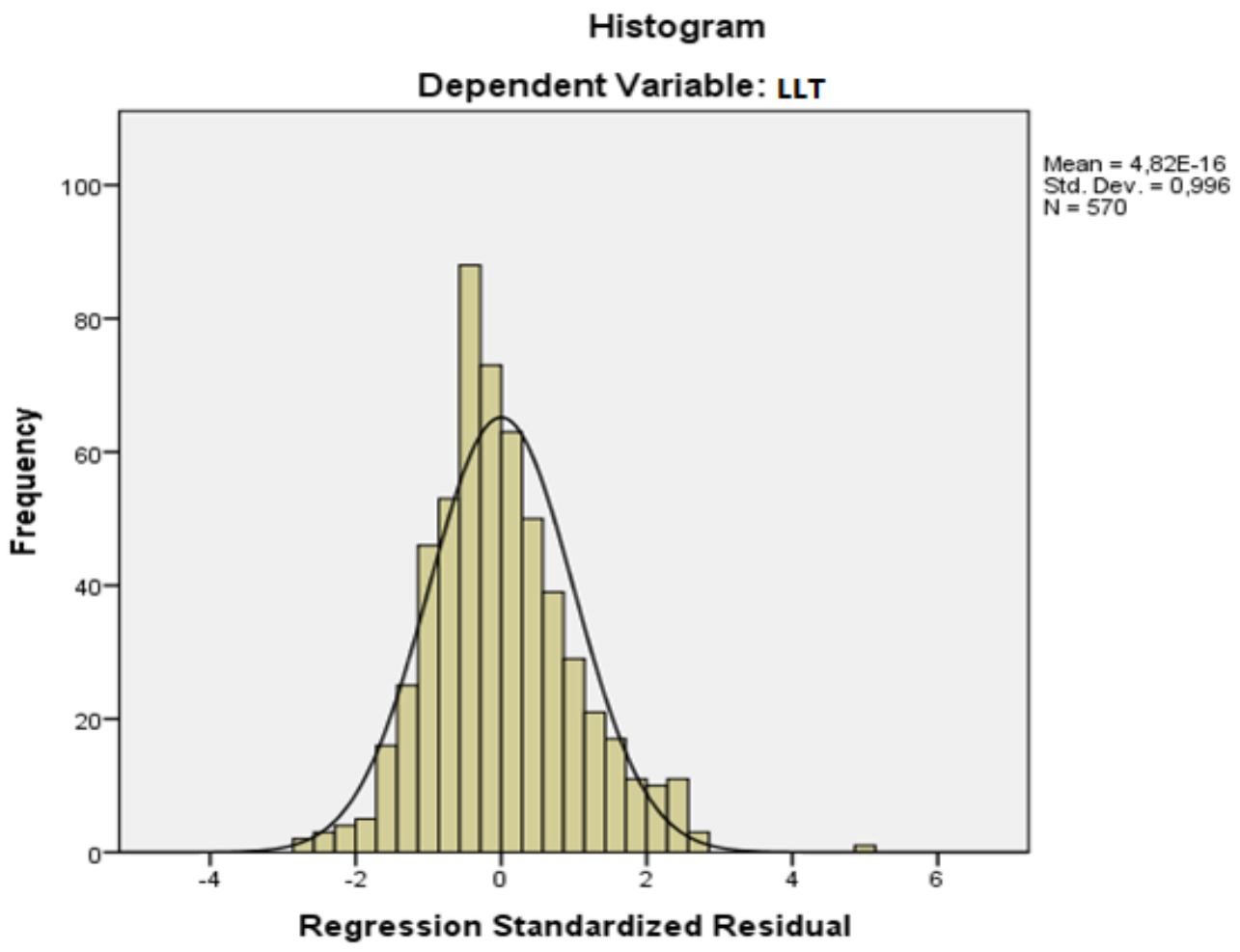

Figure 2. Histogram and normal probability plot regarding the distribution of scores

As can be seen in the above histogram, the scores are distributed normally around zero.

\section{Results, Conclusions and Recommendations}

In this study, it was found there is a low, positive correlation between lifelong learning tendency and educational philosophies scores of the subjects. As for the correlation between the sub-dimensions of educational philosophies, essentialism and perennialism have a medium level, positive correlation with lifelong learning tendency. Reconstructionism has a low and positive correlation and progressivism has a low but negative correlation with lifelong learning tendency. $18,2 \%$ of the change in lifelong learning is accounted for by educational philosophies, which means that lifelong learning tendency is weakly predicted by philosophies of education.

Lifelong learning tendency is expected to be predicted by progressivism by the researchers but a low, negative correlation was found between the two. The background of the study group may explain the positive correlation between essentialism and lifelong learning tendency and perennialism and lifelong learning tendency. That is to say, the subjects are usually university graduates or last year students. They have been educated through the curriculum under the effect of behaviourist approach. Constructivist approach has been implemented since the year 2005 in Turkey in k-12 education; however, most of the teachers resisted to the new approach and they employed behaviourist methods, which they can implement easily compared to those of constructivist approach. In conclusion, educational philosophies play a considerable role in learning and teaching. However, the studies examining the relation between these two variables are not enough in quality and quantity. So, the relation between them should be studied using different scales on different samplings.

\section{REFERENCES}

[1] Coşkun, Y. D. and Demirel, M. (2010) Lifelong learning tendency scale: the study of validity and reliability Procedia-Social and Behavioral Sciences 5, 2343-2350.

[2] Conti, G. J. (2007). Identifying Your Educational Philosophy: Development of the Philosophies Held by Instructors of Lifelong-learners (PHIL). MPAEA Journal of Adult Education Volume XXXVI, Number 1, Spring.

[3] Delors, J. (1996) Learning: The treasure within Report to UNESCO of the International Commission on Education for the Twenty-first Century, UNESCO

[4] Dewey, J. (1916). Democracy and education: An introduction to the philosophy of education. New York: Macmillan.

[5] Gajda, R. (2001). The NNER and Pre-Service Teachers' Philosophic Orientations. Unpublished doctorate thesis, Colorado State University, Colorado.

[6] Kaplan, L.S. and Owings, W. A. (2015). Educational Foundations. Stamford: Cengage Learning.

[7] Lindeman, E.C. (1926). The Meaning of Adult Education. 
New York: New Republic, Inc.

[8] Madaus, G.F., Kellaghan, T., \& Schwab, R. L. (1989). Teach Them Well: An Introduction to Education. New York: Haper\&Row.

[9] Moss, G. and Lee, C. (2010). A Critical Analysis of Philosophies of Education and INTASC Standards in Teacher Preparation International Journal of Critical Pedagogy, Vol 3 (2) pp. 36-46.

[10] Ornstein, A. C. (1991). Philosophy as a Basis for Curriculum Decisions. The High School Journal, Vol. 74, No. 2 (Dec., 1990 - Jan., 1991), pp. 102-109.

[11] Örs, Mukaddes. (2016) “İlkokul Öğretmenlerinin Yaşam
Boyu Öğrenme Eğilimlerinin İncelenmesi”. Eğitime Dönüş Ed. E.Babaoğlan, E. Kıral, A. Çilek. Ankara: EYÜDER Publications, pp. $87-101$.

[12] Sahu, B. (2002). The New Educational Philosophy. New Delhi: Sarup\&Sons.

[13] Segall, W. E. and Wilson, A. V. (2004). Introduction to Education: Teaching in a Diverse Society. Oxford: Rowman $\&$ Littlefield. Publishers, Inc.

[14] Semerci, Ç., Semerci, N. ve Çerçi, N. (2002). Eğitim-öğretim felsefesini belirleme ölçeği, XIth Educational Sciences Congress, October 23rd-26th 2002, Near East University, Lefkosa, North Cyprus Turkish Republic. 